\title{
Sustainable Design in Event Design: Opportunities and Limitations
}

\author{
S'harin Binti Mokhtar and Yi-Shin Deng
}

\begin{abstract}
Events offer valuable economic, social, cultural and educational benefits, and potential growth in tourism for many international destinations. As society gains a greater understanding about these impacts, events are being challenged to become more accountable for their managerial decisions and to produce outcomes which are more sustainable on multiple criteria and have positive environmental impacts. The purpose of this study was to discuss sustainable design in event design. Literature review will be conducted in this study as the research methodology. The aims of this study are (1) to discuss the opportunities of sustainable design in event design; (2) to discuss the limitations of sustainable design in event design. Lastly, findings from this study will provide insights on the opportunities of sustainable design in event design to develop better sustainable events in the future and limitations that have to overcome before a sustainable event been organize.
\end{abstract}

Index Terms - Sustainable design, Event Design, Opportunities, Limitations.

\section{INTRODUCTION}

The event industry has experienced extraordinary growth over the past decade in terms of the number, diversity and popularity of events on offer. Events offer valuable economic, social, cultural and educational benefits, and potential growth in tourism for many international destinations. Until very recently however, little attention has been paid to the impacts that events have on the natural and built environment. Events often involve the creation of new infrastructure; they can occur in environmentally-sensitive locations, require transport of attendees, goods and services and other scarce resources in large quantities. As society gains a greater understanding about these impacts, events are being challenged to become more accountable for their managerial decisions and to produce outcomes which are more sustainable on multiple criteria and have positive environmental impacts.

So what does it mean to design according to "sustainable" principals? Sustainability since the early 1990s has emerged as a societal "mega-trend" supported by all major sectors of the economy after World Commission for Environment and Development (WCED) prepare a document entitled Our Common Future introduced its definition says in a few words the following: sustainable development that meets of the present without compromising the ability of future generations to meet their own needs [1]. There are many viable sustainable design models that provide guidance in implementing this overarching goal. This paper firstly

Manuscript received May 15, 2013; revised July 8, 2013

S'harin Binti Mokhtar and Yi-Shin Deng are with the National Cheng Kung University, Tainan City, 701 Taiwan (e-mail: sharin2901@gmail.com, yishin.deng@gmail.com). considers the current literature on events and sustainability, and secondly, discuss the limitations and opportunities of the Sustainable Design on its application in event design, which ultimately result in both strong academic outcomes and practical skills development for event industry practitioners.

The purpose of this study was to discuss sustainable design in event design. Literature review will be conducted in this study as the research methodology. The aims of this study are (1) to discuss the opportunities of sustainable design in event design; (2) to discuss the limitations of sustainable design in event design. Lastly, findings from this study will provide insights on the opportunities of sustainable design in event design to develop better sustainable events in the future and limitations that have to overcome before a sustainable event been organize.

\section{LITERATURE REVIEW}

\section{A. Sustainable Design}

"Sustainable design is more often than not is confused with "Green" or "eco" design. There is a distinction between the two. The "Green/eco" design is the practice of reducing or eliminating environmental impacts of design, whereas sustainable design is concerned with the environment, and also with social and economic issues. Therefore, sustainable design encompasses whatever concept Green/eco design has and goes beyond encompassing ecology, economy and cultural contexts. World Commission on Environment and Development (1987) defines Sustainable Design as "meeting the needs of the present without compromising the ability of future generations to meet their needs" [1]. The intention of sustainable design is to "eliminate negative environmental impact completely through skilful, sensitive design". Manifestations of sustainable design require no non-renewable resources, impact the environment minimally, and relate people with the natural environment.

Sustainable design is the philosophy of designing physical objects, the built environment, and services to comply with the principles of social, economic, and ecological sustainability. Furthermore, the activity of design, rather than being an isolated end in itself, is an applied activity which always answers a purpose. Therefore, sustainable design leads to the development of more environmentally benign products and processes. Any form of design that minimizes environmentally destructive impacts by integrating itself with living processes is called sustainable design.

Besides that, the whole processes need to be balanced in action. sustainable design a balanced approach means: cultivate world-views, ethics and knowledge to attain triple-bottom-line goals, engaging in the development of ways to interact with stakeholders to pursue these goals and 
allocating optimum resources to support their realization. Promoting a balanced approach, industrial design can contribute with ecological and technological know-how, and with methods and tools to advance social sustainability and social inclusion [2].

Sustainable design is not specifically owned by a profession or a discipline, it is an approach to harmonize and interact with nature. Sustainable design helps us review our designs and people's daily life styles and behaviours. In short, it is an effective fit to, as well as a cohesive combination with natural processes. On this philosophic level sustainable design responds to the concept of sustainable development by raising questions about the optimal transition scenario for a more sustainable future, the idea of well-being, or the optimal status of goods [3]. By trying to overcome these differences, system design approaches become increasingly important [3].

Sustainable design should developed from the requirements of the organization to consider economic, social and environmental impact [4] from the production process until the products or services has deliver to customer. Consideration that can be made in the three components are:

1) Ecology: Introduce/take back to basics on the ecosphere. The question is not simply how to recycle materials, but how to see them in the first place--where they come from and where they go to.

2) Economy: It is economic literacy that is the cornerstone of sustainable design. What do we want to sustain, if not mindless economic growth? What ways can we move in the right direction as economic actors?

3) Social/culture: The fact that design generally pushes consumerism, and yet, for all its negative impacts, consumerism helps people create meaning. Part of culturally sustainable design is to help find alternatives to consumerism that help people generate meaning.

As conclusion, sustainable design not only focus on environment, but also economy and social. Sustainable design no longer only owned by specific field, yet it suitable to apply in any profession or discipline as long as the it responds to harmonize and interact with environment, economy and social.

\section{B. Event Design}

There are many definitions of event. Festival and events are 'for people to come together to celebrate, to demonstrate, to worship, to honor, to remember, to socialize and 'specific rituals... or celebration that are consciously planned and created to mark special occasions', and that it is 'impossible to provide a definition that includes all varieties of events'. An event is a unique moment in time celebrated with ceremony and ritual to satisfy specific needs and most common events are community related.

Planned events are spatial-temporal phenomenon, and each is unique because of the interactions among the setting, people and management systems - including design elements and the program. Planned events are all created for a purpose which encompassing festivals and other celebrations, entertainment, recreation, political and state, scientific, sport and arts events, those in the domain of business and corporate affairs (including meetings, conventions, fairs and exhibitions), those in the private domain (including rites of passage such as wedding and parties and social events for affinity groups).

As conclusion, a number of event design definitions have been offered. There are two overarching notions embedded within these definitions. The first and more widely used concept identifies event design as the overall developed concept, deals with the all-encompassing elements of the event, that is, how the event was designed in order to function successfully. The look and feel of the event; its aesthetics. The second, and more recently two notions, although different, share many similarities in terms of the overall goal of event design [5]. Design is essential to an event's success because it leads to improvement of the event on every level. Event design is the critical component, underpinning every other aspect of the event and central to event design are the core values of the event.

\section{RESEARCH METHODOLOGY}

In order to carry out this study, a literature review has been conducted to gather existing academy literature of sustainable design and event design. A literature review is a systematic, explicit, and reproducible design for identifying, evaluating, and interpreting the existing body of recorded documents. The analysis of documents pursues the aim of opening up material that does not have to be created on the basis of a data collection by the researcher. Literature reviews usually aim at two objectives: first, they summarize existing research by identifying patterns, themes and issues. Second, this helps to identify the conceptual content of the field and can contribute to theory development. The gathered data was studied to provide comprehensive summary of sustainable design and event design as background information to understand current position of event design before more in-depth study has been conducted. Then, the same method had been applied to understand in-depth of sustainable design and event design based on available literature in order to identify possible aspect in event design to discuss about sustainable design. Data collection involved gathering journal paper published on the websites. A convenience sampling process was used to identify appropriate papers for the study. Sometimes called purposive sampling, the units of study were chosen not for their representativeness but for their relevance to the research questions and analytical framework of the study [6]. The literature searching was guided by few keywords which are sustainable design and event design. Lastly, findings from this study will provide insights on the opportunities of sustainable design in event design to develop better sustainable events in the future and limitations that have to overcome before a sustainable event been organize (Fig. 1).

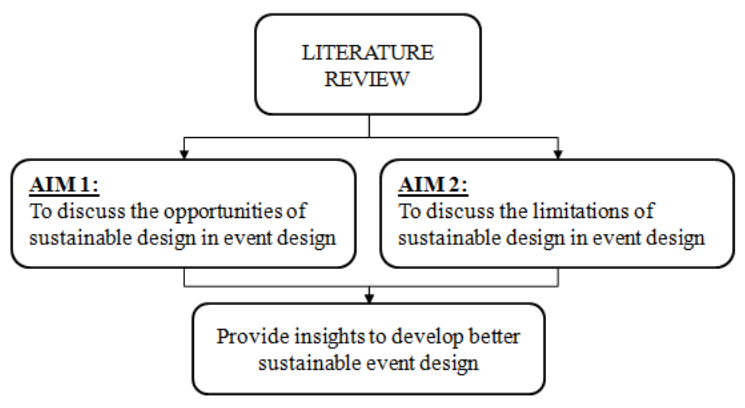

Fig. 1. Research Process. 


\section{Discussions}

Sustainability in the event industry is a "megatrend" that is influencing the industry [7]. A green meeting or event incorporates the environmental considerations to minimize its negative impact on the environment [8]. Websites, including Sustainable Communities Network, BlueGreen Meeting, and GreenMeetings.com, were created to inform the industry and promote the sustainable concept. In addition, many industry associations are implementing sustainable initiatives for their membership, including Green Meeting Industry Council, Professional Convention Management Association, and Meeting Planners International.

Although there is no specific definition of this term in the academic literature, 'greening' in the business events context is defined as "investment in sustainable practices and facilities". Examples might be reducing waste, increasing recycling, minimizing water use, using renewable energy sources, purchasing local produce, or implementing environmental management systems.

The overall starting point was mentioned in Section 1 of this paper. Both the definition of sustainability design and event design form the background of the review is conducted Section 2. The discussion will be presented in two parts, which based on the aims of this study that mentioned earlier:

- To discuss the opportunities of Sustainable Design in Event Design

- To discuss the limitations of Sustainable Design in Event Design

\section{A. Opportunities of Sustainable Design in Event Design}

Sustainable design is essential to an event's sustainability success because it leads to improvement of the sustainable practices in event on every level. Event design is the critical component, underpinning every other aspect of the event and central to event design are the core values of the event. The core values are usually built throughout the event design process. In this study, opportunities of sustainable design will be discuss through event process. Event process includes research, design, planning, coordinating, and evaluation of events [9].

\section{B. Research}

Research about existing environmental policies and strategy are needed in order to identify efforts that can be made to reduce event-related emissions of greenhouse gases and support off-setting of unavoidable emissions. Such sustainable action plan able to help the event management team to be clear with available measurable objectives (key performance indicators), responsibilities, deadlines and appropriate monitoring action to achieve sustainable practices effectively in the event. Besides that, it also will help the event team to establish their own framework of best practices that consist levels to achieve a 'sustainable' standing within the event industry.

Other than that, research about existing low impact materials and sustainable resources are needed too. Materials that are nontoxic, produced in sustainable fashion or recycled, and require little energy to process that offer in current market need to be identify before the event proposal has been created.

\section{Design}

Sustainable design begins with the intimate knowledge of a place, and protecting and saving natural capital. Event management should first consider where there are, what nature allows them to do and what help nature can provide them. They should try their best to use local natural materials because sustainable design emphasizes protection, reduction, reuse and recycle in the material (service) flow and energy flow in natural ecological system. Natural environmental system provides all kinds of conditions and processes to maintain human survival and satisfy their demands and it is possible for them to reduce the obvious environmental impact arising from design through cooperation with processes and patterns followed by life.

Secondly, a website can be create to promote sustainable concept. Event website can become a tool to inform the industry about the sustainable event and also promote sustainable event concept to maximize the effect of sustainable. The website itself can contained practical references for sponsors and visitors or other event management team which provided information on how to make an event more sustainable [10]. This able to encourage more environmentally friendly products and services been created from marketing and services perspective [11].

\section{Planning}

Planning a sustainable event requires a series of activities that must meet the client's perceptions of their event. In order to create a sustainable event, a proper event proposal is a first step to achieve the sustainable objectives. Sustainable request of proposal including sustainable practices in the decision making process should begin early, such as with the RFP (request of proposal) process. Design can be used strategically to create an sustainable event proposal [12] and it can also be the underlying principle, or blueprint that establishes the event idea and experience. Most studies explore the idea of the event concept as a starting point for developing the event idea, whereupon the sustainable event elements can be then designed to express the concept. A unifying theme such as sustainable design can be put forward as a way of connecting the design elements with the event experience. The event design process is not time consuming. The overwhelmingly positives effects of this level of planning, prior to any detailed logistical or operational planning commencement, can be quite dramatic.

Besides that, a 'sustainability team' with internal staff from the main units or departments involved in the organisation of the event and, ideally, representatives from the main stakeholder groups (e.g., host city or country, sponsors, suppliers, venue, hotel, local community, etc.) which understand the concept of sustainable design are needed in order to make sure the objectives of sustainable design that planned in the event proposal are achieved. The team member with information and knowledge of sustainable and also understand the practices of sustainable able to organize a sustainable event that not only concern about environment, but also economy and social.

\section{E. Coordinating}

To promote sustainable in event planning, developing a communication plan able to make sure other stakeholders are aware and engaged in sustainable activities - use 
communication channels to promote the sustainability of the event and engage those involved. This action also able to increase awareness of sustainable, inform and involve relevant stakeholders, including participants, the workforce, local hosts, regional and national authorities, sponsors, civil society groups, NGOs, businesses and technical experts.

\section{F. Evaluation}

An evaluation system is useful after the event to measure the progress of the sustainability activities - to quantify achievements, benchmark weaker areas and set targets and improvements for the future. Such reporting system is put in place that allows for the communication, assessment and evaluation of "sustainable event processes, initiatives and results" [13] and also a checklist to help stakeholders to examine the sustainable of the event.

As conclusion, understanding and embracing the core sustainable design of an event gives that event a clear direction that is easily marketed and easily understood by all those involved, whether internal or external to the organization. It is clearly understood by the event management team that every decision made must related back to, and be in accord with the core values for the event. Therefore, embedding sustainable design throughout the event design process may be a necessary step in the development of sustainable events. Identifying areas where the industry can focus crucial planning efforts will help enable successful future sustainable development in order to stay environmental friendly within the event industry.

\section{G. Limitations of Sustainable Design in Event Design}

Even though there are many opportunities was discovered when discussing sustainable design in event design process, however, there still some limitations of sustainable design in the application of event design.

In order to achieve sustainable in event design, is should be start from organizer that willing to organize an event that implement these practices. However, due to poor return of investment, some of the organizers refuse to practice sustainable in the event they organize. Organizers notice that tourist or visitor not willing to pay more to get sustainable event because visitors not optimistic for low carbon tourism. Paying for sustainability or greening is not something that tourists (business or leisure) are particularly willing to do.

The above reason are cause by lacking of customer interest in sustainability. Sponsors believe that a move to 'green practices' would diminish the quality of the events even though there is wrong; there has been 'evidence of a growing customer interest'. Sponsors appear to be less supportive [14] - they perceive that the atmosphere and look of green meetings appears somewhat cheaper, or perhaps less exclusive than non-green or traditional meetings. Besides that, not all attendees have the same perceptions and attitudes towards the idea of sustainable.

Thirdly, organizers and sponsors lack of information and knowledge on sustainable. Very little is being done to encourage event managers to ensure the event they are organising is sustainable as there is little operational and strategic training or accreditation on offer to members [15]. Organizers and sponsors struggle to understand the jargon and vague definitions used for sustainability and how it can help not only their event but also the overall environment.
However, even though event management teams may not have the information readily available to them, there are research showed that they were interested in learning and understanding more about the practices [16].

Even though some organizers or sponsor understand the practices of sustainable in event design, most of them could not bear with the extra costs compare to organizer and ordinary event. Many sustainable practices may have an initial cost that may be too high for event organizers to justify. Previous research has identified that financial issues (both cost and time involved) have emerged as the main barrier to greening [17].

The extra costs in organize a sustainable event sometimes cause by lacking of resources and/or infrastructure. Existing infrastructures are suitable for current event without sustainable practices. Many older properties were not designed with this environmental friendliness in mind. Therefore, retrofitting an entire facility may not be realistic due to cost consumption. Besides that, organizers having difficulties to get sustainable resources to support such practices. Infrastructure needed to implement certain practices may be unavailable or too expensive to put in [16].

\section{CONCLUSIONS}

Events are standard business practice for the simple reason that they are often the most time efficient and effective way of sharing thinking, identifying solutions and reaching agreement. As society gains a greater understanding about these impacts, events are being challenged to become more accountable for their managerial decisions and to produce outcomes which are more sustainable on multiple criteria and have positive environmental, ecology and social impacts.

In order to reduce the impact of event towards environment, ecology and social, this study had discuss the possible opportunities of sustainable design through event design process. Among the findings that gathered from this study are research about existing environmental policies and strategy, research about existing low impact materials and sustainable resources, design the event with the intimate knowledge of a place, and protecting and saving natural capital such as try their best to use local natural materials, promote and provide practical sustainable references to sponsors and visitors to encourage more environmentally friendly products and services been created from marketing and services perspective, including sustainable practices in the RFP (request of proposal) process, a 'sustainable team' that understand the concept of sustainable design, develop a communication plan able to make sure other stakeholders are aware and engaged in sustainable activities and an evaluation system to measure the progress of the sustainability activities after the event.

The benefits of incorporating sustainability considerations into event planning can be manifold. Sustainability considerations lead to environmental improvements, financial advantages, creating a positive image for the event planners, and social benefits for the local community. They can also trigger secondary positive effects such as innovation in the marketplace, thereby stimulating new product growth; and by raising awareness and inspiring change they can create long-term benefits for the broader community. 
However, implementation of sustainable design in event design constraint by some limitation such as poor return of investment, lack of sustainable information, lack of customer interest in sustainability, cost of implementation are high, lack of resources or infrastructure and financial restrictions.

The findings from this research have move the research agenda forward and provide insights to develop better sustainable event design through event design process and some limitations that might faced by stakeholders in event industry when sustainable design had been practice. To overcome the limitation and fully implement the sustainable concept in event industry to get better opportunities, cooperation from all the stakeholders is needed.

\section{ACKNOWLEDGMENT}

The author wishes to express her gratitude to her Supervisor, Dr. Yi-Shin Deng who was abundantly helpful and offered invaluable assistance, support and guidance.

\section{REFERENCES}

[1] WCED. Our Common Future, Oxford: Oxford University Press, 1987.

[2] M. Keitsch, "Sustainable design: A brief appraisal of its main concepts," J. Sustainable Development, vol. 20, pp. 180-188, 2012.

[3] B. Bramwell, B. Lane, "Editorial: Priorities in sustainable tourism research," Journal of Sustainable Tourism, vol. 16, no. 1, pp. 1-4, 2008.

[4] C. Vezzoli and E. Manzini, Design For Environmental Sustainability, London: Springer, 2008.

[5] G. Berridge, Events Design and Experience, Elsevier, New York, NY, 2007.

[6] T. A. Schwandt, Dictionary of Qualitative Inquiry, 2nd ed. Sage Publications, California, 2001.

[7] J. Mair and L. Jago, "The development of a conceptual model of greening in the business events tourism sector," Journal of Sustainable Tourism, vol. 18, no. 1, pp. 77-94, 2010.

[8] Resource Smart, Victorian Government. (February 21, 2012). [Online]. Available: http://www.resourcesmart.vic.gov.au/.

[9] R. M. Convene. (April 30, 2009). from Professional Meeting Planners Association. [Online]. Available: Http://www.pcma.org/Convene/IssueArchives/March2008/Megatrend s.htm

[10] C. Dickson and C. Arcodia, "Promoting sustainable event practice: The role of professional associations," International Journal of Hospitality Management, vol. 29, pp. 236-244, 2010.
[11] R. Hard, Incorporate Elements of Sustainability And Recycling Into Hotel Vendor Contracts. Retrieved April 30, 2011. [Online]. Available: http://eventplanning.about.com/od/conferenceservices/qt/hotel-contra cts.htm

[12] B. Rittichainuwat and J. Mair, "An Exploratory Study of Attendee Perceptions of Green Meetings," Journal of Convention \& Event Tourism, vol. 13, pp. 147-158, 2012.

[13] C. Dickson and C. Arcodia, "Promoting sustainable event practice: The role of professional associations," International Journal of Hospitality Management, vol. 29, pp. 236-244, 2010.

[14] Green Seal, Greening the Lodging Industry Program. Retrieved January 26, 2011. [Online]. Available: http://www.greenseal.org/programs/lodging.cfm

[15] S. Bergin-Seers and J. Mair, "Emerging green tourists in australia: Their behaviours and attitudes," Tourism and Hospitality Research, vol. 9, pp. 109-119, 2009.

[16] J. Draper, M. Dawson, and E. Casey, "An exploratory study of the importance of sustainable practices in the meeting and convention site selection process," Journal of Convention \& Event Tourism, vol. 12, no. 3, pp. 153-178, 2011.

[17] J. Mair and L. Jago, "The development of a conceptual model of greening in the business events tourism sector," Journal of Sustainable Tourism, vol. 18, no. 1, pp. 77-94, 2010.

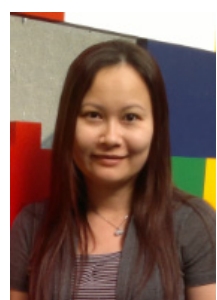

S'harin Binti Mokhtar received the MA in Art \& Design (Design Technology) and BA (Hons) of Art \& Design (Industrial Design) from Department of Industrial Design, Faculty of Art \& Design, University Technology MARA, Malaysia.

She has worked as a lecturer in Department of Industrial Design, Faculty of Art \& Design, University Technology MARA, Malaysia for 4 years and currently working toward the Ph.D. degree at the Institute of Creative Industries Design, National Cheng Kung University, Taiwan. Her research interest is in Product Design and Sustainable Design.

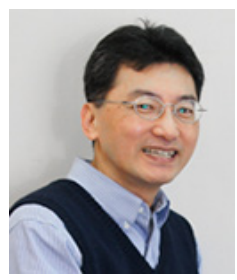

Yi-Shin Deng received his Ph.D. and M.Sc. in Industrial Engineering from Department of Industrial Engineering, University of Pittsburgh, Pennsylvania, United States.

$\mathrm{He}$ is an associate professor of the Institute of Creative Industries Design at National Chen Kung University, Taiwan. He is an active researcher and instructor on topics including human-computer interaction, user experience design, social informatics, design theory and methodology and computational design. Other research and practice on applying user research approach and exploration design processes to ICT device design, social software platform development, and service design are also his research interest. 